\title{
INTER-FACILITY CORRELATIONS OF TRANSONIC TEST RESULTS OF THE AGARD-C STANDARD WIND-TUNNEL MODEL
}

\author{
Dijana Damljanović ${ }^{1}$, Jovan Isaković ${ }^{2}$ Marko Miloš ${ }^{3}$ \\ 1 Military Technical Institute (VTI), Experimental Aerodynamics Department, Ratka Resanovića 1, \\ 11030 Belgrade, Serbia. E-mail: didamlj@gmail.com \\ 2 Tehnikum Taurunum, College of Applied Engineering Studies, Nade Dimić 4, 11000 Zemun \\ Belgrade, Serbia. E-mail: jisakovic@tehnikum.edu.rs \\ 3 University of Belgrade, Faculty of Mechanical Engineering, Department of General Machine Design, \\ Kraljice Marije 16, 11120 Belgrade, Serbia. E-mail: $\underline{\text { mmilos@mas.bg.ac.rs }}$
}

\section{Introduction}

Periodical wind-tunnel testing of standard models is an important item in a health monitoring of the wind-tunnel structure, instrumentation and flow quality. A series of tests of an AGARD-C standard model was performed in the $1.5 \mathrm{~m} \mathrm{~T}-38$ trisonic wind-tunnel of the Military Technical Institute (VTI) in Belgrade. The tests comprised measurements of forces and moments in the transonic Mach number range with the purpose of correlating the model's obtained aerodynamic characteristics with those from other wind-tunnel laboratories. Inter-facility correlations are part of an adopted procedure for standard models testing in VTI experimental facilities, [1]. VTI finds it important to obtain these standard wind-tunnel data which serve to ascertain the stability of the measurement process and are helpful in future tests of similar configurations (especially with the Ttail). Also, an intention of the authors is to expand the database of published test results of this model, which is somewhat smaller than the one for the well-known AGARD-B model, [1].

\section{Methods}

\subsection{Wind-tunnel facility}

The T-38, the most powerful test facility in the VTI, Belgrade, Serbia is a trisonic blowdown-type pressurized wind-tunnel with a $1.5 \mathrm{~m}$ square test section, Fig.1.

Mach number in the range 0.2 to 4 can be achieved in the test section, with Reynolds numbers up to $110 \times 10^{6}$ per metre. In the subsonic configuration, Mach number is set by sidewall flaps in the tunnel diffuser. In the supersonic configuration, Mach number is set by the flexible nozzle contour, while in transonic configuration, Mach number is both set by sidewall flaps and the flexible nozzle, and actively regulated by blow-off system. Mach number can be set and regulated to within $0.5 \%$ of the nominal value.

Stagnation pressure in the test section can be maintained between 1.1 bar and 15 bar, depending on Mach number, and regulated to $0.3 \%$ of nominal value. Run times are up to $60 \mathrm{~s}$, which depend on Mach number and stagnation pressure.

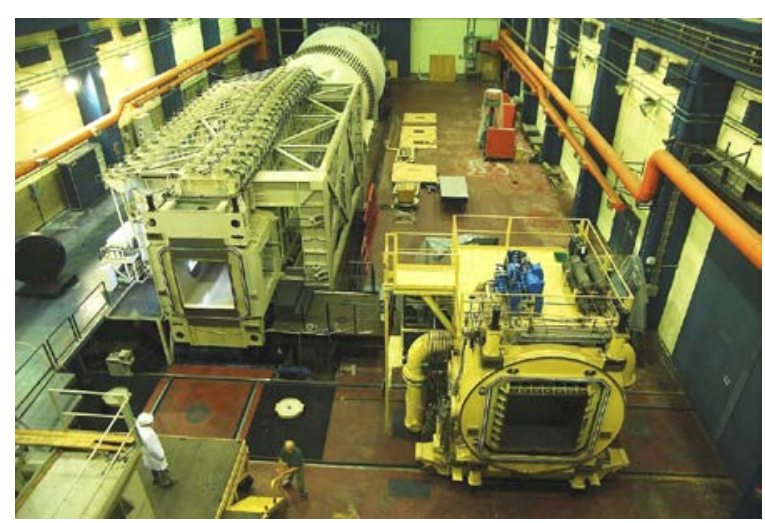

Fig. 1. T-38 wind-tunnel facility in VTI, Belgrade.

Model is usually supported in the test section by a tail sting mounted on a pitch-and-roll mechanism. The facility supports both step-by-step and continuous model movement during measurements.

\subsection{Standard AGARD-C model}

Standard AGARD-C model, a derivative of the well-known standard AGARD-B model [2], is an ogive-cylinder with a delta wing and a horizontal and a vertical stabilizer in the T-tail configuration, Fig.2.

The AGARD-C standard model, used in T-38, was supplied by Boeing and model size of 115.8 $\mathrm{mm}$ dia. was chosen with respect to the tunnel's 


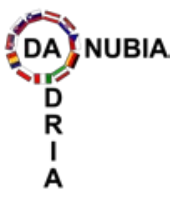

34th Danubia-Adria Symposium on Advances in Experimental Mechanics

University of Trieste, Italy, 2017 test section size. Model had been used in previous $\mathrm{T}$-38 wind-tunnel calibrations and tests in other wind-tunnels. A large database is available in the VTI for inter-facility correlations.

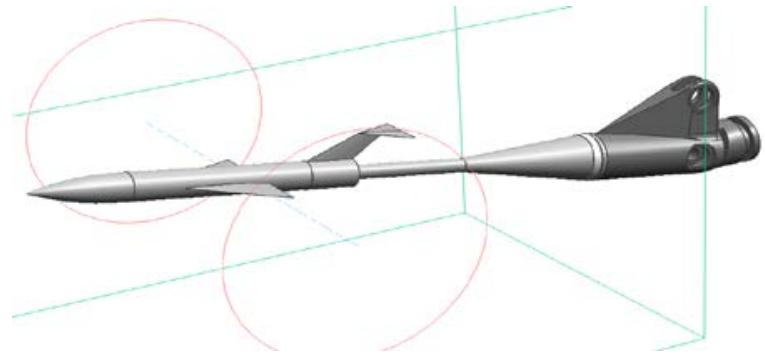

Fig. 2. CAD rend. of the AGARD-C model used in VTI.

\section{Results}

The new T-38 tests have been performed at the transonic Mach numbers 0.7 to 1.15 at moderate angles of attack traversed by the continuous pitching movement of the AGARD-C during the run.

Inter-facility correlations were based on test results of physically the same model (the 115.8

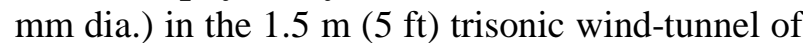
the National Research Council (then operated as National Aeronautical Establishment) of Canada, in the $1.2 \mathrm{~m}$ trisonic wind-tunnel of the Romanian National Institute for Scientific and Technical Creation (INCAS, later INCREST) and in the T-38 wind-tunnel during the commissioning period. Correlated test results are presented in the wind axes system in Fig. 3 and Fig. 4, showing forebody drag-force and pitching-moment coefficients as function of the angle of attack. Test results are given for the model aerodynamic center. Model reference length is the mean aerodynamic chord.

It should be noted that, because of the smaller size of the INCREST test section the blockage of the AGARD-C model in tests was higher than in VTI and NAE tests. Also, according to INCREST, there was insufficient ventilation of the plenum chamber causing the boundary layer to be too thick in the high transonic regime, which has affected the measurement of the pitching-moment. The AGARD-C model is known for the high sensitivity of the pitching-moment to local conditions.

\section{Remarks}

A good agreement of the correlated test results has been found, which confirms a high flow quality in the T-38 test section, good condition of the wind-tunnel structure and instrumentation and the correctness of the data reduction algorithm.
Making visible the standard test results provides a general benefit to the experimental aerodynamics community.
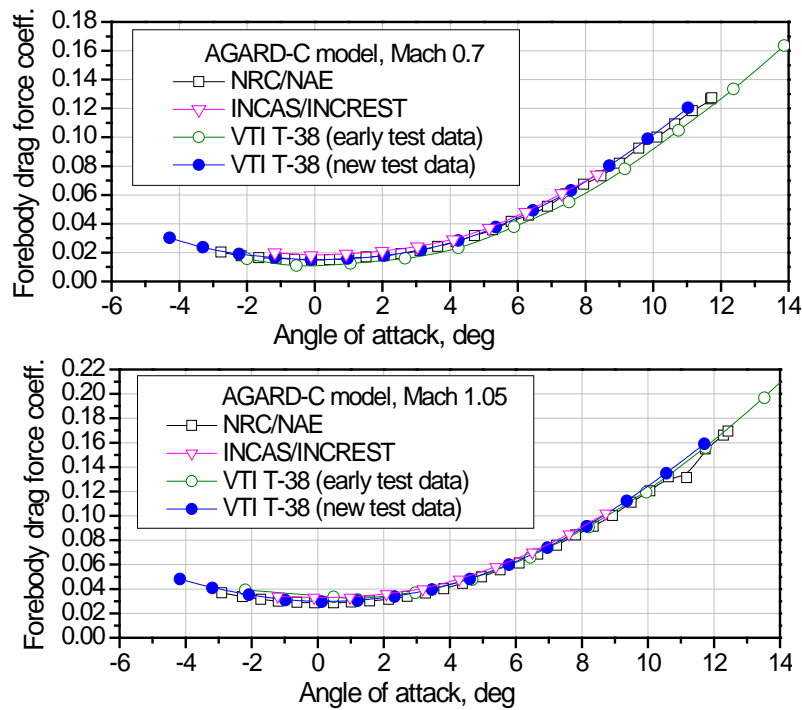

Fig. 3. Inter-facility correlations in the drag-force measurements, Mach 0.7 and 1.05.
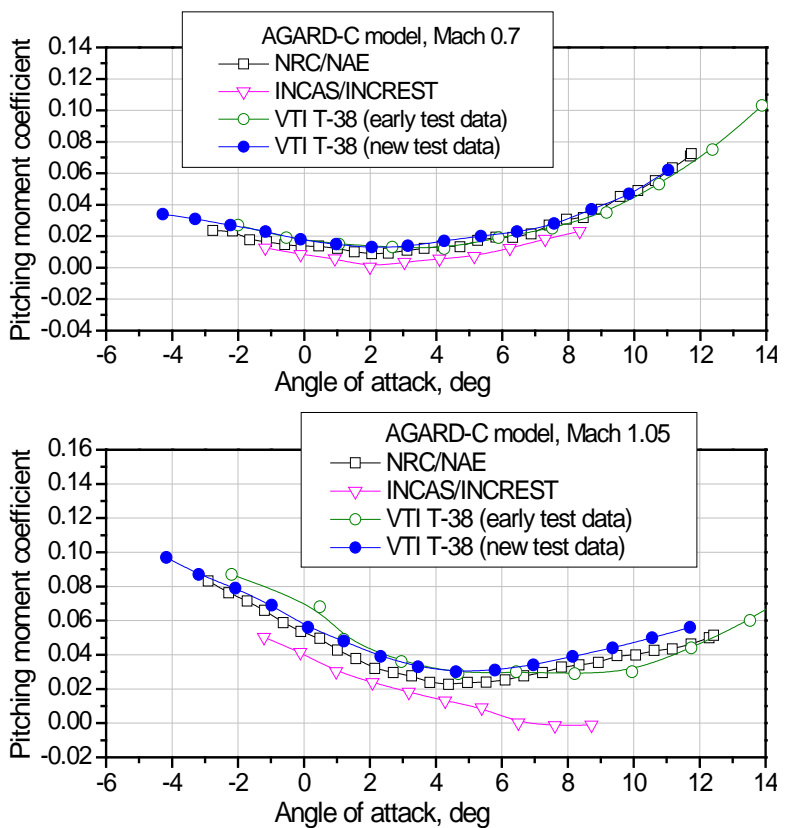

Fig. 4. Inter-facility correlations in the pitching-moment measurements, Mach 0.7 and 1.05.

\section{References}

[1] Damljanovic, D., Isakovic, J., Rašuo, B., T-38 Wind-Tunnel Data Quality Assurance Based on Testing of a Standard Model, Journal of Aircraft, 50 (4), 2013. pp. 1141-1149.

[2] Hills, R., A Review of Measurements on AGARD Calibration Models, AGARDograph 64, Aircraft Research Association, Bedford, England, 1961. 